Rev. Hist., N²6, vol. 1, Enero-junio 2019: 29 -57

ISSN 0717-8832

\title{
El Partido Nacional: de su origen, disolución y receso, al malestar (1966-1983) ${ }^{1}$ \\ The National Party: from its origin, dissolution and recess to its discomfort (1966-1983)
}

Sergio Sepúlveda Sepúlveda*

\section{RESUMEN}

El artículo analiza el desarrollo del Partido Nacional como fuerza política, especialmente su situación tras el receso político y la autodisolución en 1973, y como vivió durante el receso partidista la actividad política de sus principales representantes, los que empezarían a mostrar discrepancias con el régimen cívico militar chileno que gobernaba el país entonces, a raíz de la aplicación de diversas políticas. Se concluye que el Partido Nacional si bien apoyó el Golpe de Estado, no estuvo comprometido con las principales decisiones políticas al estar marginado de la toma de decisiones, teniendo como efecto, que las principales figuras empezaren a mostrar señales de disensión contra el Régimen y empezase a matizar la diferencia entre la derecha histórica con los grupos que estaban surgiendo al alero del régimen cívico militar Chileno.

Palabras claves: Partido Nacional, régimen cívico militar, Receso, Disidencia

\section{ABSTRACT}

The article analyzes the development of the national party as a political force, especially the situation after the political recess and self-dissolution in 1973, and how the political activity of its main representatives lived during the partisan recess, which would begin to show discrepancies with the Chilean Military Civic Regime that ruled the country. The research concludes that the National Party, although it supported the coup, did not commit itself to the main political decisions by being marginalized from the decision-making process. As a consequence, the main figures began to show signs of dissidence between the historical right wing and the groups that emerged under the aegis of the Chilean Military Civic Regime.

Keywords: National Party, Chilean Military Civic Regime, Recess, Dissidence.

Recibido: diciembre 2018

Aceptado: junio 2019

\footnotetext{
${ }^{1}$ Esta publicación es resultado de mi tesis de Magíster en Historia por la Universidad de Concepción, titulada: “Una disidencia derechista al régimen cívico militar chileno: Partido Nacional (1983-1988)".

*Magister en Historia, Universidad de Concepción. E-mail: sergsepulveda@udec.cl
} 


\section{Introducción}

Tras los sucesos del golpe de estado producido el 11 de septiembre de 1973, se instauró un régimen autoritario de la mano de los militares y los civiles que le apoyaron. Esto provocó como efecto inmediato el fin de la vida política partidista y el control del país y de los poderes públicos por parte de la Junta Militar.

A los días, el Partido Nacional manifestó su apoyo al Golpe de Estado. La directiva, encabezada por Sergio Onofre Jarpa, declaró el receso y autodisolución de la colectividad, otorgando a sus militantes libertad de acción, quienes se concentraron en sus actividades privadas, o bien, en el caso de algunos de ellos, ocupando cargos de segunda línea o de menor relevancia en el nuevo régimen.

En tanto fue transcurriendo el tiempo, se observa que los ex Partido Nacional perdieron injerencia en el núcleo gobernante, por el rol que asumieron los gremialistas junto a los tecnócratas neoliberales, muy especialmente en el desarrollo de la vida pública a nivel de gobierno, como en las instituciones y en la gestión económica. Se suma a ello que, no se observó atisbo alguno de volver al régimen democrático previo al Golpe de Estado.

Por otra parte, a fines de la década de 1970 principiaría a aflorar el malestar en algunos de los cuadros del ex Partido Nacional, quienes comenzaron a disentir del régimen, manifestando algunos personajes connotados sus opiniones críticas por medio de la prensa escrita o a través de entrevistas. Su disconformidad con el régimen se debía tanto a la situación política del receso político, a la falta de libertades, como por la aprobación a regañadientes del plebiscito constitucional en 1980. Se agrega la crítica a la gestión económica de los "Chicago Boys", como también lo concerniente a las características de la represión política a propósito de los Derechos Humanos.

De lo anterior, para guiar el trabajo de investigación surgieron una serie de preguntas que servirán para responder los objetivos del trabajo: ¿Qué sucedió efectivamente con el Partido Nacional tras el golpe de estado? ¿Cómo surgen los elementos que contribuyeron al desarrollo de una disidencia de derecha frente al régimen cívico militar?

Lo dicho en los párrafos anteriores permite que el trabajo se centre en la unidad de análisis que es el Partido Nacional y sus militantes y ex militantes connotados que hacen manifestación de su posición por medio de la prensa a través de entrevistas, o las notas que hacen del Partido Nacional los medios escritos, y las opiniones de los diversos autores que han trabajado la historia del Partido Nacional en la historiografía, por cuanto ellos son los sujetos históricos que identifican un modo de ser político que vuelve a emerger en la vida pública con posterioridad a 1978. 
Por lo tanto en este estudio, se busca explicar que sucedió con el Partido Nacional tras su disolución, como también distinguir y analizar las razones del surgimiento de la disidencia derechista al régimen cívico militar ${ }^{2}$ al interior del ex Partido Nacional.

La hipótesis que se plantea para ese trabajo es que los ex militantes del Partido Nacional, si bien apoyaron el Golpe de Estado del 11 de septiembre de 1973, no dejaron de tener en su fuero interno, la esencia democrática previa al quiebre de la institucionalidad, desmarcándose de los grupos partidarios del régimen cívico militar chileno que gobernó el país de 1973 a 1990.

Cabe agregar algunas reflexiones con relación a los aspectos teórico-metodológicos. El trabajo tiene una naturaleza explicativa del surgimiento de un grupo de personas de derecha disidentes del régimen cívico militar, al alero del Partido Nacional. El desarrollo se sustenta en el método histórico desde un prisma cualitativo utilizando un enfoque de historia política en que se estudia el desarrollo de un conglomerado político, a través de la recopilación, crítica y análisis de diversas fuentes y de la bibliografía referida a este referente político.

Se tomaron aspectos teóricos del enfoque de la Nueva Historia Política ${ }^{3}$. De acuerdo a Moyano ${ }^{4}$, la NHP constituye un intento de reformular y recuperar el sitial de importancia en la producción historiográfica, teniendo en cuenta las transformaciones de carácter epistemológicas, como también metodológicas, en que los nuevos contextos permiten una preocupación por los actores políticos del pasado. Se considera también hacer emerger las experiencias guardadas en las memorias de esos testigos mediante el uso de la perspectiva de

\footnotetext{
2 Timmermann, Freddy.2015. El Gran Terror. Miedo, Emoción y Discurso. Chile, 1973-1980. Ediciones Copygraph, Santiago, pp. 27-28. Se utiliza este concepto de régimen cívico militar por cuanto tras el golpe de Estado que promovieron los civiles y llevaron a cabo los militares en día 11 de septiembre de 1973, "el rol de los civiles que apoyaron a las FFAA fue igual o superior al de los militares en las funciones de gobierno; es por eso que los civiles encuadrados en los grupos gremialistas organizaron el espacio administrativo y jurídico, mientras los tecnócratas neoliberales lo hicieron desde el prisma económico, sumando en ello a la antigua oposición a la Unidad Popular, especialmente algunos grupos de Demócrata Cristianos y ex militantes del Partido Nacional, el Poder Judicial, los cuadros de algunos ministerios, la Prensa y algunos ex militantes de Patria y Libertad."

3 Moyano, Cristina. 2011. "La historia política en el bicentenario: entre la Historia del Presente y la Historia Conceptual. Reflexiones sobre la Nueva Historia Política", Revista de Historia Social y de las Mentalidades N 15 p. 228. Ponce, José y Pérez, Aníbal. 2013. "La Revitalización de la historiografía política chilena", Polis Revista Latinoamericana $\mathrm{N}^{\circ}$ 36, pp. 453-476. Monsalvez, Danny. 2012. "La dictadura militar de Augusto Pinochet como Nueva Historia Política: Perspectiva historiográfica y algunos temas para su indagación", Revista Austral de Ciencias Sociales $\mathrm{N}^{\circ} 23, \mathrm{pp} .61-82$.

${ }^{4}$ Moyano, Cristina. 2011. "La historia política en el bicentenario..., op.cit., pp. 227-245 y su obra, en la que desarrolla de manera completa su postura teórica historiográfica en Moyano, Cristina. 2010. El MAPU durante la Dictadura. Saberes y prácticas políticas para una microhistoria de la renovación socialista en Chile, 1973-1989, Universidad Alberto Hurtado, Santiago, , pp. 15-101.
} 
la historia del tiempo presente. Ello se manifiesta con los siguientes cambios en que se han redefinido una serie de elementos teóricos claves, que son ${ }^{5}$ :

1. Los objetos de estudios siguen siendo los partidos políticos, sumados como comunidad de actores diversos.

2. Mayor énfasis en la discusión histórica de los conceptos e ideas políticas con un trabajo más colaborativo con otras disciplinas como las ciencias sociales.

3. La Nueva Historia Política ha realizado cruces con la Historia Social a través de coincidir con el uso de la memoria como elemento clave de trabajo con el pasado y avances en el uso de las fuentes, en este caso de las memorias y testimonios de los militantes de la fuerza que ha sido objeto de estudio, entre otros.

Para este artículo, ese enfoque permitió desarrollar el trabajo al pesquisar fuentes de información en que militantes del Partido Nacional opinaron sobre el régimen cívico militar, y para ello la revisión de entrevistas impresas fue fundamental, por cuanto recogían sus percepciones y puntos de vista efectuados en el momento, sin las distorsiones que pudo provocar el haber entrevistado en vivo a los protagonistas en años posteriores. En este caso la mayoría de los involucrados están fallecidos y los que sobreviven poseen una avanzada edad. Además, el trabajar con parte de los ex-militantes como fuente de información permite independizarse de la historiografía cuando ella no aborda el tema de estudio; la bibliografía sirvió para trabajar el contexto, salvo casos muy puntuales que sirvieron para contribuir al estudio de la trayectoria del Partido Nacional en el periodo de estudio ${ }^{6}$.

En segundo lugar, el concepto de Derecha Política que se presenta permitió entender cómo el Partido Nacional se formó como un partido político emergente en 1965, para enfrentar una contingencia adversa, ser en el gobierno de Allende uno de los líderes en la oposición y partidario del golpe de Estado; y posteriormente, diferenciarse de los nuevos grupos de derecha y partidos políticos formados al alero del régimen cívico militar.

\section{El nacimiento de la Derecha moderna: el Partido Nacional y el gobierno de Eduardo Frei}

El triunfo de Eduardo Frei en la elección presidencial de 1964, si bien, a juicio de Correa, provocó un colapso de la derecha histórica, no causó temor; es más, Valdivia señala que trató de ganar tiempo induciendo al gobierno a negociar los proyectos de ley, pero en vísperas de la pronta elección parlamentaria, el gobierno fue quitando las urgencias a los proyectos de ley, a

\footnotetext{
${ }^{5}$ Moyano, Cristina: “La historia política en el bicentenario..., op.cit., p. 230.

${ }^{6}$ Sepúlveda Sepúlveda, Sergio. 2018. Una disidencia derechista al régimen cívico militar chileno: Partido Nacional (1983-1988). Tesis de Magister. Universidad de Concepción, Concepción, pp. 10-14.
} 
la espera de los resultados de la elección parlamentaria de marzo de $1965^{7}$. Estas elecciones fueron un triunfo contundente del Partido Demócrata Cristiano (PDC) sobre sus adversarios, especialmente el Partido Radical y la derecha histórica, que bajaron considerablemente su votación, siendo perjudicados los liberales y especialmente los conservadores. El PDC logró la mayoría de la Cámara de Diputados y un tercio del Senado; por otro lado, la derecha quedó prácticamente reducida a una mínima expresión.

Lo anterior no provocó desaliento en palabras de Valdivia, sino que la dirigencia pensaba que se estaba repitiendo nuevamente el fenómeno ibañista que anunciaba el fin de los partidos políticos, tirando por la borda la tesis de la izquierda que habría decretado la muerte de la derecha; sin embargo, en la época, de boca de varios de sus adeptos, existía la noción de que la derecha política siempre existiría, porque era una filosofía de vida, una doctrina y principios vitales para el desarrollo del país ${ }^{8}$. No obstante, la calma de la derecha con el gobierno duró hasta junio de 1965, cuando este impulsó la legislación de los proyectos de reformas constitucionales y de Reforma Agraria, que afectarían el derecho de propiedad ${ }^{9}$.

La situación provocó una discusión interna en el seno de la derecha, y en palabras de Arellano, se concluyó que "la opción más adecuada para enfrentar ese nuevo escenario es fusionar todas las colectividades o construir un nuevo referente político". Este planteamiento dio origen al Partido Nacional ${ }^{10}$.

El partido Nacional jugó un papel interesante en el sistema político a partir de tres ideas ${ }^{11}$ : Allan Angell dice que el Partido Nacional fue más un proyecto defensivo contra el marxismo que un nuevo proyecto de derecha; Corvalán Marqués manifiesta que el Partido Nacional surge dentro del contexto de los proyectos globales a fines de 1950, y que su rol fue representar los proyectos de corte capitalista; Correa da cuenta de que el Partido Nacional es una muestra de la destrucción de la derecha histórica por la pérdida de influencia y del control del Estado desde un punto de vista político, al no tener margen de maniobra desde el Congreso Nacional. De otra parte, Mario Valdés clarifica que Conservadores y Liberales

\footnotetext{
${ }^{7}$ Correa, Sofía. 2005. Con las riendas del poder. La derecha chilena en el siglo XX, Sudamericana, Santiago, p.301; Valdivia, Verónica. 2008. Nacionales y Gremialistas. El parto de la nueva derecha política chilena, 1964-1973. LOM Editores, Santiago, p. 71.

${ }^{8}$ Valdivia, Verónica. 2008. Nacionales y Gremialistas, pp. 71 y 78.

9 Fernández, María Elisa. 2017. "Conformación de Partidos Políticos en Chile”. En Iván JAKSIC y Juan Luis OSSA (editores): Historia política de Chile, 1810-2010 Tomo I: Prácticas Políticas. FCE, Santiago, p.166.

${ }^{10}$ Arellano, Juan Carlos. 2009. "El Partido Nacional en Chile. Su rol en el conflicto político (1966-1973), en ATENEA $\mathrm{N}^{\circ} 499$, p. 158.

11 Ibidem, p. 159.
} 
coincidieron en que había que renovarse para contener los "extremismos" e "interpretar grandes masas", las que no se sentían expresadas por la política existente ${ }^{12}$.

Por lo tanto, existió una búsqueda de definición de estrategias frente a la polarización política, compartiendo con Valdés que la renovación es una estrategia para la que el Partido Nacional debe actuar con fuerte pragmatismo ${ }^{13}$.

Nacionalistas, conservadores y liberales coincidían en rechazar a la derecha económica, definida por Rafael Otero como la conformada por los grandes monopolios, trust, "y los grandes intereses de grupo que desconocen toda moral o interés nacional"; un "tumor" que hay que extirpar por constituir una fuente de inmoralidad. El industrial, el trabajador independiente, el profesional, el empresario independiente $-\mathrm{y}$ todos los que no viven de un sueldo burocrático- no forman parte de esa derecha económica.

Lo dicho comienza a tomar forma cuando los partidos Liberal y Conservador deciden fusionarse e invitan a otros grupos como Acción Nacional para asimilar a los nacionalistas con los grupos democráticos y configurar una nueva derecha. Con el acto realizado el 10 de mayo en el Club de Septiembre (la sede del PL), se inició la transformación de dicha institución en Partido Nacional.

En la sesión presidida por Jorge Errázuriz se leyó la declaración de principios de la nueva colectividad política. En ella se identificaba al Partido Nacional con los valores de la civilización occidental y cristiana, junto a su oposición al marxismo. Se propiciaban mayores facultades para el Presidente de la República y una mayor participación de las fuerzas armadas en el desarrollo nacional, especialmente en lo educativo, técnico y económico. La "clase media" era calificada como el estrato fundamental de la sociedad chilena. Planteaba la declaración también, la necesidad de recuperar el cobre y el hierro para Chile, calificando de injusto el mejor trato dado por el país a los capitales extranjeros.

El Partido Nacional surgió como un partido renovador y nacionalista que buscaba un nuevo orden centrando su interés en la clase media. Como partido programático, el Partido Nacional diagnostica que el auge de la izquierda y la intransigencia de la DC buscarán transformar el orden social existente, por lo que se ve la inminencia de una crisis nacional y para ello el nacionalismo sería un escudo frente a los discursos modernizadores del centro y la izquierda ${ }^{14}$.

Para lograr lo anterior, el nuevo bloque se presenta en palabras de Rubio, con una propuesta novedosa en comparación con los fenecidos partidos Liberal y Conservador, tanto

\footnotetext{
12 Valdés Urrutia, Mario. 2015. El Partido Nacional: 1966-1973. Tesis Doctoral, Universidad Nacional de Educación a Distancia (UNED), Madrid, p. 72.

${ }^{13}$ Ibídem, pp.81-83.

${ }^{14}$ Arellano, Juan Carlos. 2009. "El Partido Nacional”, p.161.
} 
del punto de vista de la retórica renovadora (del discurso de Los nacionalistas) y de la movilización social, al convocar las capas medias y los independientes, reafirmando lo dicho por Valdés ${ }^{15}$.

Así mismo se puso como meta, buscar un piso electoral para las elecciones de 1970, por lo cual se recalca nuevamente la importancia de la clase media para el Partido Nacional, y para lograr esa adhesión empieza a jugar un rol de oposición enérgica a las reformas estructurales, acusando a los DC de totalitarios y de profundizar la crisis nacional, dejando claro que el Partido Nacional utilizó en el periodo de Frei el régimen institucional, pero bajo una mirada muy crítica del sistema democrático, para rechazar la Reforma Agraria y defender el derecho de propiedad ${ }^{16}$.

También se criticó la sindicalización campesina, la promoción popular y otras iniciativas de Frei por considerarlas altamente ideologizadas y que buscaban aumentar el poder del Estado. Arellano complementa que si bien se aprecia el carácter democrático del Partido Nacional, no es menor la labor de desgastar al gobierno en el Senado, donde tenían una leve ventaja sobre aquel y lograr con ello erosionar su apoyo.

Desde punto de vista del esquema político, el Partido Nacional es antimarxista y busca responder al avance del PC como también detener a la izquierda y al mismo avance del PDC.

En 1967 se produce la primera prueba electoral del Partido Nacional en las elecciones municipales y se apela al aporte que puede hacer en política a partir de un enfoque moderno y responsable para hacer frente al Gobierno. La campaña y el resultado permite crearse un espacio dentro del espectro político realizando un rol de oposición bastante definido, con un camino propio sin alianzas, desarrollando críticas a la DC y a la izquierda, logrando con ello reencontrar a su viejo electorado y sumar a los desencantados con el gobierno sin volver a ser la vieja derecha; al contrario, reforzando su rol de nueva derecha lo cual se plasmaba más cerca de las elecciones, criticando también cada vez más a la $D C^{17}$. Se recuperó algo de la vitalidad de la derecha, alcanzando el $14,3 \%$ de la votación general, manteniendo su influencia en las provincias del centro y sur del país, espacios donde tradicionalmente tuvo su base política.

El Partido Nacional pensaba que el país vivía una crisis política, económica y moral. La crisis se expresaba en el Gobierno, el PDC y en los partidos de izquierda; todos envueltos en una competencia de demagogia. EI PDC caminaba supuestamente hacia el totalitarismo, donde identificaba la acción del gobierno con sus fines electoralistas y partidistas, por el control que

\footnotetext{
15 Rubio, Pablo. 2013. Los Civiles de Pinochet. La derecha en el Régimen Militar Chileno, 1983-1990; DIBAM, Santiago, pp. 58-59

${ }^{16}$ Arellano, Juan Carlos. 2009. “El Partido Nacional”, p.161; Rubio, Pablo. 2013. Los Civiles de Pinochet, p. 59.

${ }^{17}$ Arellano, Juan Carlos. 2009. "El Partido Nacional”, p.165.
} 
sus militantes ejercían desde el presidente hasta los activistas que se han "injertado en la administración pública ${ }^{18}$.

Para las elecciones parlamentarias de 1969, el Partido Nacional se pudo consolidar como fuerza política relevante a nivel nacional, conquistando el $20 \%$ del electorado, y neutralizando el impacto de la pérdida del voto rural que pasó a la DC, como de sus antiguos clientes que dependían de los artilugios electorales ${ }^{19}$.

El Partido Nacional, como nuevo partido de acción, logró esta primera vez elegir 34 diputados y 5 senadores. Logró elegir 25 diputados más que los partidos Conservador y Liberal,

considerados en conjunto como su antecedente inmediato. En 1965 la derecha obtuvo 9 diputados. Pero los nacionales estaban muy distantes del apoyo popular que la derecha alcanzaba en los años treinta cuando su respaldo oscilaba entre el 30 y $40 \%$ del apoyo electoral a nivel nacional.

Estos resultados permitieron mejorar las opciones para la campaña presidencial de 1970, participando activamente en la de Jorge Alessandri y en la formulación del programa "la Nueva República" en que se incorporan los postulados para salir de la crisis provocada -a su juicio- por la política sectaria de la DC.

Para la elección de 1970 los nacionales apoyaron la opción presidencial de Jorge Alessandri y optaron por seguir la lucha democrática; pero fracasaron en evitar el triunfo de Allende, y lo declararon al negarse a reconocerlo como futuro Presidente antes y durante la convocatoria al Congreso Pleno ${ }^{20}$.

\section{El Partido Nacional y la Unidad Popular}

La llegada de Allende y su programa de transformaciones tuvo como consecuencia que los nacionales desarrollaran una capacidad movilizadora y de presión a partir de 1971. Para cumplir con ello, elaboraron una estrategia para enfrentar a la Unidad Popular, que consistió en ser una "oposición integral y ampliada", teniendo un cariz de radicalizada en el sentido de lograr la deslegitimación del gobierno. Para lograrlo, consideraron desarrollar tres ámbitos: 1 . Electoral: buscar acuerdos con la DC, para enfrentar al gobierno en un único frente, lo cual se concreta después de las municipales de 1971, cuando se enfrentan a la UP en diversas elecciones complementarias, gremiales y finalmente en la elección parlamentaria de 1973. 2. En el Congreso, a través de las acusaciones a los diversos ministros cuando infringían alguna normativa, o en el rechazo a las iniciativas de ley oficialistas. 3. Medios de prensa: como

\footnotetext{
${ }^{18}$ Valdés Urrutia, Mario. 2015. El Partido Nacional, pp. 138-139.

${ }^{19}$ Rubio, Pablo. 2013. Los Civiles de Pinochet, p. 61. Correa, Sofía. 2005. Con las riendas del poder, p.311.

${ }^{20}$ Arellano, Juan Carlos. 2009. “El Partido Nacional”, p.166. Rubio, Pablo. 2013. Los Civiles de Pinochet, pp. 63-64.
} 
instrumento de denuncia contra la gestión de las autoridades y para generar rechazo al gobierno.

Por otro lado, Corvalán plantea que la derecha llevó a la práctica una estrategia rupturista para llevar al país a la crisis institucional, apelando a la defensa de valores, especialmente el de la libertad ${ }^{21}$.

Un tema que tuvo el gobierno de la UP, fue la minoría parlamentaria con la que contaba, por lo que hizo uso de las diversas facultades presidenciales, especialmente para intervenir en el sector económico, causando el rechazo de la oposición, especialmente del Partido Nacional, que también se opuso al proceso de aceleración de la Reforma Agraria, que trajo consigo las expropiaciones y diversos episodios de violencia rural, dentro de lo que señala Contreras, "una defensa de sus valores de clases...", presentando esa defensa de valores como pertenecientes a la sociedad nacional ${ }^{22}$.

Gobierno y Oposición le dan a lo largo del periodo a las diversas elecciones, el carácter de plebiscitarias, en las que se aprueba o rechaza la gestión realizada por la administración política $^{23}$, aplicando entonces los ámbitos ya señalados para desarrollar una oposición efectiva, buscando el acercamiento y apoyo de la DC, y de los gremios.

Con la "marcha de las cacerolas vacías", se da inicio a una nueva fase del rol de la oposición del Partido Nacional, al buscar la desestabilización del gobierno. Para lograr ese objetivo, comienza el acercamiento a la sociedad civil, haciendo un abierto llamado a la movilización general para denunciar el descontento y generar un clima de ingobernabilidad ${ }^{24}$.

Lo dicho se justifica con los sucesos del año 1972 y tiene su punto álgido con el paro de los camioneros en octubre de ese año, el cual contó con el apoyo de la oposición en pleno, mostrando un simbólico rechazo al gobierno y a su programa. También el Partido Nacional aprovecha el momento para responsabilizar al Gobierno de la situación política conflictiva imperante.

En 1973, los desencuentros políticos comienzan a agudizarse y eso provoca un aumento del descontento. El Partido Nacional se concentró en las elecciones parlamentarias de marzo, en las que si bien la oposición resultó con mayoría de los votos, no logró reunir los 2/3 de los escaños del Senado para destituir a Allende, por lo que continuó con el proceso de

\footnotetext{
${ }^{21}$ Corvalán M, Luis. 2002. Del anti capitalismo al neoliberalismo en Chile. Izquierda, centro y derecha en la lucha entre los proyectos globales, 1950-2000. Sudamericana, Santiago, p. 505.

22 Corvalán M, Luis. 2002. Del anti capitalismo al neoliberalismo, p. 505; Contreras Mario, y González Eduardo2014. Las derechas en Chile (1958-1981), Ediciones Universidad de Valparaíso, Valparaíso, p.14-

23 Arellano, Juan Carlos. 2009. "El Partido Nacional”, p.168. Valdés Urrutia, Mario. 2015. El Partido Nacional, pp.199-205 y 278-290 profundizan los procesos eleccionarios durante la Unidad Popular, tanto a nivel municipal (1971), como las parlamentarias de 1973 y mencionando las elecciones complementarias efectuadas.

${ }^{24}$ Arellano, Juan Carlos. 2009. "El Partido Nacional”, p.170. Corvalán M, Luis. 2002. Del anti capitalismo al neoliberalismo, pp. 506-507.
} 
desestabilización social y de deslegitimación del gobierno. Esto cimentó el paso a una nueva etapa: el quiebre institutcional, lo que se lograría al desarrollar un ambiente de polarización general ${ }^{25}$.

Mario Valdés explica que la arremetida política de la oposición en contra del gobierno, en el caso del Partido Nacional, se expresó de diversas formas. Se advirtió con nitidez a propósito de la oposición al proyecto de Escuela Nacional Unificada (ENU); con motivo del apoyo a la huelga de los trabajadores del cobre, y a consecuencia de la sublevación del Regimiento Blindados $\mathrm{N}^{\circ} 2$, el 29 de junio de $1973^{26}$. En junio de ese año, el Partido Nacional declaraba el quiebre con Allende, producto del veto al proyecto de ley "Hamilton-Fuentealba" ${ }^{27}$, aprobado por la oposición. Posteriormente el Partido Nacional reaccionó declarando que: "Allende deja de ser el Presidente Constitucional del país", dirigiéndose a las FFAA para que interviniese ${ }^{28}$.

El 7 de mayo de 1973 la Corte Suprema se dirigió al Presidente de la República, representándole el desobedecimiento de Carabineros a resoluciones de los tribunales de justicia, grave hecho que conducía a una "crisis del Estado de Derecho" en el país. El 23 de agosto, la Cámara de Diputados declaró que el Gobierno estaba actuando al margen de la ley, y ese acuerdo aprobado por la oposición buscó como resultado una salida a la crisis a través de mecanismos extra constitucionales, al representar a los oficiales de las FFAA que formaban parte del gobierno, debía oponerse a todas las situaciones que infringían la Constitución y la ley ${ }^{29}$.

El día martes 11 de septiembre se concreta el Golpe de Estado, cuyo apoyo declaraba el Partido Nacional, como asimismo, gran parte de la oposición. Ese día se declaran cerradas las Cámaras hasta nueva orden y se da comienzo a un largo receso político.

\section{El Partido Nacional y el receso (1973-1983)}

El Gobierno de Allende fue derrocado por medio de un Golpe de Estado el día 11 de septiembre de 1973 y los militares asumieron el poder a través de la Junta Militar de

\footnotetext{
${ }^{25}$ Rubio, Pablo. 2013. Los Civiles de Pinochet, pp. 64-66. Mario Valdés hace un recuento detallado de los resultados electorales de 1973, especialmente de los escaños obtenidos por el Partido Nacional, y las consecuencias en la contingencia política, véase Valdés Urrutia, Mario. 2015. El Partido Nacional, pp. 280 y ss.

${ }^{26}$ Valdés Urrutia, Mario. 2015. El Partido Nacional, pp. 290 y ss., explica el proceso final de la oposición del Partido Nacional al Gobierno de Allende.

${ }^{27}$ Reforma Constitucional aprobada que transfiere al Congreso la facultad de decidir sobre el paso de empresas al área social, es decir, buscaba restringir las expropiaciones.

${ }^{28}$ Arellano, Juan Carlos. 2009. "El Partido Nacional”, p.171

${ }^{29}$ El oficio de la Corte Suprema al Presidente de la República de 7 de mayo y el de la Cámara de Diputados al mismo destinatario, de 23 de agosto de 1973, se encuentran en: Bravo Lira, Bernardino, Régimen de Gobierno y partidos políticos en Chile 1924 - 1973, Santiago, Jurídica, 1978, pp.225 - 226 y 257 - 261, respectivamente. Véase además, Rubio, Pablo. 2013. Los Civiles de Pinochet, p.70; Arellano, Juan Carlos. 2009. "El Partido Nacional”, p. 171; Corvalan M, Luis. 2002. Del anti capitalismo al neoliberalismo, p. 280.
} 
Gobierno, a partir de los diversos bandos y Decretos Leyes emitidos desde ese mismo día. Frente al nuevo panorama político, los nacionales declaran su apoyo a la actuación de los militares, quienes asumieron el gobierno con un rasgo de carácter rupturista y refundador. Esto se sustenta en la búsqueda que tuvieron las FFAA de lograr el poder total y por lo tanto supeditar a todos los grupos políticos a su acción ${ }^{30}$.

Lo dicho se plasma en los bandos que declararon en receso las Cámaras y en la prohibición de toda actuación política con la instauración del Estado de Sitio.

Las fuerzas armadas como grupo político surgen sin tener experiencia ni proyecto político, pero si por tener un "alto nivel de unidad institucional, organización jerárquica y eficaz, una segregación física y psicológica respecto a la civilidad, una mentalidad controvertida respecto a los partidos políticos" ${ }^{\prime 31}$. Lo anterior deriva que al instalarse, como señala Timmermann, lo haga con apoyo de una coalición variopinta que logró sintonizar apoyos que iban más allá del Partido Nacional ${ }^{32}$, teniendo las fuerzas armadas como eje de una mentalidad política global el nacionalismo, y el respeto a la propiedad privada, al catolicismo, a las jerarquías sociales y a la disciplina laboral ${ }^{33}$.

El espíritu de refundación con el que llegó a gobernar la Junta Militar se explica, según Rubio, a que interpretó de alguna manera el programa de la derecha de 1970, sin ser conducida por los políticos, sino que por los propios militares ${ }^{34}$. Esto daría lugar a una situación de mimetismo por el apoyo activo de la derecha al nuevo régimen, señalando que los militares no gobernaron solos, sino que sectores de la derecha, sin compromiso, apoyaron y colaboraron especialmente en las áreas de transformación económica.

Pese a ese mimetismo, no hubo duda del alejamiento del Régimen con respecto a los hombres públicos, a los cuales rechazaba por lo sucedido en el sistema político previo al Golpe de Estado y como representación de los vicios de un sistema que debía reestructurase ${ }^{35}$; para ello los diversos bandos y decretos leyes fueron los brazos legales para conformar el nuevo armazón institucional, a lo que el Partido Nacional dio un apoyo expreso sustentado en diversas publicaciones del diario Tribuna, siendo interesante la declaración del 14 de septiembre, en la que declara tácitamente el fin del Partido Nacional ${ }^{36}$ :

\footnotetext{
${ }^{30}$ Rubio, Pablo. 2013. Los Civiles de Pinochet, pp. 71-72.

${ }^{31}$ Cañas K, Enrique. 1997. Proceso Político en Chile 1973-1990, Andrés Bello, Santiago, p.64.

${ }^{32}$ Timmermann, Freddy. 2015. El Gran Terror, p. 64.

33 Cañas K, Enrique. 1997. Proceso Político, pp.64, 65.

34 Rubio, Pablo. 2013. Los Civiles de Pinochet, p.73.

${ }^{35}$ Rubio, Pablo. 2013. Los Civiles de Pinochet, pp.74-75.

${ }^{36}$ Ibidem, p.76.
} 
“... Los nacionales, que durante estos años aciagos hemos estado en la primera fila de la lucha, volvemos hoy a tomar las herramientas de trabajo con la satisfacción del deber cumplido, con renovada fe en el destino de Chile, y guardando en nuestros espíritus, el recuerdo imperecedero y ejemplar de todos los compatriotas que cayeron luchando en las múltiples jornadas que llevaron a la liberación de la patria.

A las Fuerzas Armadas y Carabineros de Chile les reiteramos nuestro reconocimiento y les auguramos éxito en la patriótica decisión de renovar el impulso creador de la nacionalidad" ${ }^{37}$.

Si bien el Partido Nacional, especialmente el grupo nacionalista, se cuadró con el Régimen al mostrar simpatías con respecto al concepto de democracia orgánica, estimaba que la participación de los chilenos no debía estar influida por el ambiente político partidista de la fenecida democracia liberal, ni debía recaer en sus vicios. La Junta Militar debía gobernar el país a partir del cumplimiento de metas en desmedro de los plazos, y hacer énfasis en los apoyos personales, según los nacionales, para no contaminar la gestión de las Fuerzas Armadas.

Además se debe tener en cuenta que la lucha que dio el Partido Nacional a la Unidad Popular fue también, desde la visión de los nacionalistas, para acabar con el Chile ficticio de la politiquería, y que el Chile real, el del trabajo, volviera a primar ${ }^{38}$.

Jarpa en una columna escrita en los últimos días del diario Tribuna, expresó interesantes ideas relacionadas con lo indicado previamente ${ }^{39}$ : “... El gobierno Marxista no es el origen de los males de Chile, fue solo la última etapa de un largo periodo de decadencia, originado en factores diversos. El marxismo logró infectar todo el organismo nacional, cuando estaba debilitado por dolencias crónicas que venían desde antes...". Esas dolencias estaban referidas a la pérdida del sentido de nacionalidad, a la politiquería, a la influencia foránea, la burocracia excesiva, el estatismo y la inoperancia; que fueron temas que denunció el Partido Nacional durante el gobierno de Frei. Continuando con lo anterior, la declaración señalaba que: “... No bastó en consecuencia haber liberado a Chile de la opresión marxista. Ahora es necesario realizar la segunda etapa de esta tarea histórica: reorganizar las instituciones del estado para ponerlas a tono con las exigencias y posibilidades del presente y del futuro y renovar el impulso vital y la capacidad creadora de los chilenos...". Para esa renovación apela a lo planteado por el partido dentro de sus orientaciones, pero plantea que no debe volverse al

${ }^{37}$ PARTIDO NACIONAL, declaración "Junta Militar abre una nueva etapa histórica" Diario Tribuna, Santiago, 21 de septiembre de 1973.

${ }^{38}$ Valdivia, Verónica. 2006. Su revolución contra nuestra revolución. Izquierdas y derechas en el Chile de Pinochet (1973-1981), LOM Editores, Santiago, p. 33.

39 Jarpa, Sergio Onofre: ¿Cuánto tiempo debe gobernar la Junta Militar?, Diario Tribuna, 24 de noviembre de 1973. 
viejo juego político partidista porque impediría lograr los fines para arreglar el país: “...volveríamos a dar prioridad al país político que divide, derrocha, debilita y corrompe, y a postergar nuevamente al país real que trabaja, se esfuerza, sufre y espera...". Ello significaba entonces que era tiempo de trabajar para una nueva etapa que surgía en el país, sin considerar tiempos para participar en elecciones para no estorbar el esfuerzo de las nuevas autoridades; terminando su columna con lo siguiente: “...Cuando se nos pregunte: ¿cuánto tiempo debe gobernar la Junta Militar? Contestamos: tanto como sea necesario".

Debemos tener presente que no necesariamente hubo consenso entre el Partido Nacional y los militares en los primeros días del nuevo gobierno; ello se debió a apreciaciones diferentes sobre el momento que se vivió. Esto, porque los nacionales pensaban que la Junta Militar restablecería la institucionalidad quebrantada, lo cual, como se sabe no ocurrió, y no llegaría a suceder. Debemos recordar que la Junta Militar prontamente habló más bien de realizar una labor refundacional, alejada del espectro político partidista ${ }^{40}$.

Sin embargo, respecto al fin del Partido Nacional en los días posteriores al Golpe, se tiene claro que la declaración al diario Tribuna fue la muestra clara de su autodisolución, y como señaló posteriormente Engelberto Frías “...Nosotros funcionamos hasta el último y cuando se decretó el receso del Parlamento y de la actividad política, cerramos las puertas. Fue una manera de colaborar con un Gobierno que nos interpretaba" ${ }^{41}$. Pero ello, tal como se ha creído hasta hace no mucho tiempo, no fue un receso consensuado por la elite del partido, sino que al contrario, fue tomado por una sola parte de la dirigencia según tres posiciones que muestran finalmente las dos almas que tenía el partido, desde su formación instrumental en 1966 y que se detalla a continuación ${ }^{42}: 1$. La postura de los ex senadores Fernando Ochagavía y Patricio Phillips (del bando liberal-conservador) que no querían la disolución del Partido Nacional, con la finalidad de poder influir en el régimen y evitar dar ventaja a los partidos que estaban en receso pero que clandestinamente seguían funcionando, como lo fueron los partidos integrantes de la Unidad Popular; 2. La posición del ex senador Francisco Bulnes (bando liberal-conservador), que si bien aceptaba el receso, apelaba a buscar mecanismos para poder influir en el Régimen a través de ideas; 3. La perspectiva del presidente del Partido Nacional, Sergio O. Jarpa y los nacionalistas, que acataron el receso y apostaron a la autodisolución por cuanto estimaron que el Partido Nacional ya no tenía razón de existir. En 1983 Jarpa dijo: "El Partido Nacional fue una movilización patriótica para detener el avance

\footnotetext{
${ }^{40}$ Valdés Urrutia, Mario. 2015. El Partido Nacional, p.321. Rubio, Pablo. 2013. Los Civiles de Pinochet, p.75.

${ }^{41}$ Frías, Engelberto: "El gobierno debe llamar a hora a los grupos políticos que pueden apoyarlo", Revista Cosas $\mathrm{N}^{\circ} 160,18-11-1982$, pp. 34-35.

${ }^{42}$ Valdivia, Verónica. 2006. Su revolución contra nuestra revolución. v.1, p. 39. Rubio, Pablo. 2013. Los Civiles de Pinochet, p.78.
} 
marxista y el curso decadente de la política chilena. Cumplido este propósito, disolvimos el partido y cada uno volvió a sus actividades particulares..." ${ }^{43}$.

Respecto a los viejos liberales-conservadores, el golpe fue bien recibido, se colocaron a disposición del nuevo gobierno, pero fueron ignorados. Patricio Phillips señalaba en 1979: “... en la noche del 12 de septiembre de 1973 nos ofrecimos para ir a Naciones Unidas, [Andrés] Zaldívar o [Juan] Hamilton (democratacristianos), [Humberto] Aguirre Doolan (Radical) y Yo, sin que nos pagaran para explicarle al mundo lo que pasaba en Chile. El primer día nos dijeron que bueno y después nos dijeron no, porque son políticos..." ${ }^{44}$.

Francisco Bulnes apoyó la salida golpista, pero apelando a un gobierno transitorio en que se debía corregir el sistema político con la vigencia de la Constitución de 1925, enfrentándose a la visión de los nacionalistas, que negaban la democracia liberal.

Estos grupos fueron marginados del debate público en la década de 1970, siendo desplazados por los elementos de la nueva derecha que se forjaba con el régimen cívico militar ${ }^{45}$.

Si bien posteriormente en diversas entrevistas los antiguos miembros del Partido Nacional señalaron que la autodisolución fue un error porque fue algo impuesto y se acató ${ }^{46}$; quedando solo lo referente a saldar deudas de campañas y varios; tema aparte fue lo referido al Club Domingo Fernández Concha, que funcionaba como entidad social y siguió vigente, tratando de mantener la orgánica del Partido Nacional, eligiendo a Carmen Sáenz como su presidente, pero las normas del receso sepultaron la actividad política ${ }^{47}$.

Lo dicho anteriormente tiene como efecto que sus dirigentes y militantes abandonan la política activa y se concentraran en sus actividades profesionales; y los menos, ocuparon cargos en el gobierno, pero de segunda línea o alejado de las tomas de decisiones ${ }^{48}$. Con ello, entonces, se tiene el fin de la derecha tradicional como un ente organizado y como referente político, que acepta las condiciones no democráticas que impone el nuevo Régimen Militar ${ }^{49}$. Por otro lado, en años posteriores, el profesor Andrés Benavente opinó que el Partido

\footnotetext{
43 Jarpa, Sergio Onofre: "Actualmente nadie puede atribuirse la representación del Partido Nacional”, Revista Cosas $\mathrm{N}^{\circ}$ 167, 24-2-1983, p.11. Ver también Arancibia, Patricia. 2000. Jarpa: conversaciones políticas. Ediciones Mondadori-La Tercera, Santiago, pp 199-201. En esta entrevista hace mención respecto al receso acatado por el Partido Nacional

44 Phillips, Patricio: "Los liberales nos estamos organizando en todo el país", Revista Cosas 16-8-1979, pp. 16-18.

${ }^{45}$ Cañas K, Enrique. 1997. Proceso Político, pp.66, 67.

${ }^{46}$ Valdivia, Verónica. 2006. Su revolución contra nuestra revolución. v.1, p.39

${ }^{47}$ Ibidem, p.39

48 Ibidem, p. 33.; Mario Valdés, en su tesis doctoral hace una síntesis de los principales militantes del Partido Nacional que ocuparon cargos públicos de relativa importancia durante el Régimen Militar. Valdés Urrutia, Mario. 2015. El Partido Nacional, pp. 322-325.

${ }^{49}$ Cañas K, Enrique. 1997. Proceso Político, p. 65.
} 
Nacional abdicó tempranamente de ser el cauce orgánico de la derecha al comenzar el régimen, pues no solo optó por disolverse antes de tiempo, sino que la derecha tradicional entregó el poder y el control del Partido Nacional a un grupo minoritario como lo fueron los nacionalistas con Jarpa ${ }^{50}$.

Con los sucesos señalados se tiene como resultado el triunfo del sector nacionalista por sobre el eje liberal-conservador, por lo que la derecha nuevamente entró en disonancia interna con quienes apoyaron el nuevo régimen y fueron partidarios de demorar el retorno a la democracia versus quienes vieron el nuevo gobierno como un paréntesis ${ }^{51}$.

Por otro lado, frente a aquello, Carlos Reymond, ex conservador y vicepresidente del Partido Nacional en 1973, afirmó en 1982 que si bien el receso le pareció razonable, "nunca pensamos que iba a ser largo. En ese instante solo pensamos que el país estaba en ruinas, que había que reordenarlo con urgencia y que, para ello, el Gobierno Militar necesitaba de la oportunidad de conseguir una pacificación de los espíritus" ${ }^{\prime 52}$.

El acatamiento del receso, según Valdivia, tuvo que ver con la historia del Partido Nacional y su misión como partido instrumental a partir de tres elementos: el anti marxismo; un enfoque nacionalista para solucionar problemas; y finalmente, presentar al debate público los proyectos que verdaderamente interesaban a la nación ${ }^{53}$.

Como la postura nacionalista fue la que triunfó, la actividad política se mantendría dentro de los canales que darían los órganos del nuevo gobierno y obviamente haciendo énfasis en los apoyos y cooperación para llevar a la práctica su proyecto autoritario de gobierno en un régimen de naturaleza semejante $\mathrm{y}$, con ello, "dar comienzo a una nueva etapa en la historia" ${ }^{54}$. Ello se sustentaba en una visión de que las FFAA debían lograr la unidad nacional, terminando con los odios políticos logrando la restauración nacional y la armonía social. Esta se lograría al acabar la pobreza y su semillero de incubación de las ideas marxistas, a través de la acción resuelta de un plan conectado de todos los organismos públicos responsables de la pobreza; y así mismo, fomentando el respeto a la propiedad privada y a la iniciativa particular, trayendo por efecto, el desarrollo social $\left.\right|^{55}$.

Los párrafos anteriores muestran algunos puntos de confluencia entre el Partido Nacional con las nuevas autoridades de facto, pero a medida que el nuevo régimen comienza a

\footnotetext{
${ }^{50}$ Benavente, Andrés: "La derecha anda en busca del espacio perdido "Revista Cosas, 4-11-1982, pp. 78-79

${ }^{51}$ Valdés Urrutia, Mario. 2015. El Partido Nacional, p. 321; Rubio, Pablo. 2013. Los Civiles de Pinochet, pp.76-77; Valdivia, Verónica. 2006. Su revolución contra nuestra revolución. v.1, pp.17-18.

52 Reymond Carlos: "Los chilenos no vamos a volver al marxismo. No somos un pueblo de interdictos o débiles mentales". Revista Cosas, 17-6-1982, pp. 16-17.

${ }^{53}$ Valdivia, Verónica. 2006. Su revolución contra nuestra revolución. v.1, pp. 33,34.

${ }^{54}$ Ibidem, pp. 34,35.

${ }^{55}$ Ibidem, p. 37.
} 
funcionar, ya se empezaban a observar matices en esos puntos de concordia y ello permitirá entender los fenómenos que ocurrieron a partir de 1983.

Parte de estos matices se observan no solo en el trato peyorativo a los "señores políticos", sino que también en los hechos, por cuanto la Junta Militar excluyó de los puestos de primera línea a todos los vinculados con el Partido Nacional, situación que se verá hasta el año 1983. Ese espacio, desde el punto de vista político es el que ocuparon los gremialistas.

El proyecto nacionalista fue absorbido por el Régimen militar, salvo lo referente a la movilización social, que los militares prácticamente restringieron ${ }^{56}$; y también lo que criticaban los nacionales del sistema democrático liberal, los militares lo retomaron con el discurso de Chacarillas en 1977 y después en la Comisión Ortúzar que redactó la propuesta de constitución de 1980.

En el caso de los estudios de Rubio, compartimos la opinión que el Régimen Militar no gobernó con la derecha tradicional como se cree popularmente, sino que se apoyó en una alianza entre gremialistas y tecnócratas neoliberales como los Chicago Boys, que no se formaron en torno a los viejos partidos políticos ${ }^{57}$.

Esta "coalición neoliberal civil" que señala Cañas, influyó tanto en los militares como en la marcha de la administración del Estado, destacándose especialmente por dos situaciones ${ }^{58}$. En primer lugar, el impulso a un programa de reformas socioeconómicas y político institucionales, logrando la adhesión de los grupos económicos existentes en la época, haciendo uso del poder total de la política. En segundo lugar, la nueva derecha fue capaz de penetrar vastos sectores de la sociedad y crear una nueva cultura social, que la termina enfrentando con la vieja derecha partidaria tradicional, según Correa Sutil.

La alianza se materializó en los mecanismos de acción de ambos grupos, que desplazaron a la vieja derecha. Los gremialistas tuvieron como feudos la Secretaria General de Gobierno, la Oficina de Planificación (ODEPLAN), la Secretaria Nacional de la Juventud, los municipios y parte de la Comisión Ortúzar; en cambio, los Chicago estuvieron en el Banco Central y en los ministerios de Hacienda y Economía.

Entonces, el régimen cívico militar forzó el silencio en la vida política partidista que no solo fue hacia la ex izquierda gobernante; sino que a los que los legitimaron, como fue el caso del Partido Nacional. Ello tuvo como efecto que los militares, al tener el control total del país, dejaron de lado a los actores políticos, y en el caso de la derecha, con la autodisolución, se complejizó su caracterización frente al emerger de estos nuevos grupos ${ }^{59}$.

\footnotetext{
${ }^{56}$ Valdivia, Verónica. 2006. Su revolución contra nuestra revolución. v.1, p.38.

${ }^{57}$ Rubio, Pablo. 2013. Los Civiles de Pinochet, pp. 80, 81,85.

${ }^{58}$ Cañas K, Enrique. 1997. Proceso Político, pp. 66-68.

${ }^{59}$ Ibidem, pp. 66-70; Rubio, Pablo. 2013. Los Civiles de Pinochet, pp. 80-84.
} 


\section{La Derecha post Partido Nacional surgida en el régimen cívico militar}

En los adherentes civiles del régimen, la vieja retórica liberal-conservadora se hizo historia, y los nacionalistas están ad portas de volver a su histórico destierro; sin embargo a medida que se consolida el régimen cívico militar, comienzan a notarse las diferencias, y esas discrepancias llevan a la formación de los "duros" y los "blandos", resucitando la vieja cultura política de la derecha de dividirse en bandos. Como explica Cañas, pese a la autodisolución del Partido Nacional, sobreviven rasgos culturales político partidistas que habían representado a la derecha en su pasado; así también la relación de grupos sociales afines que Correa Sutil menciona en sus obras ${ }^{60}$, y Cañas describe como grandes y pequeños propietarios, burguesía, profesionales $y$, trabajadores afines a las ideas del régimen cívico militar ${ }^{61}$.

Los duros eran aquellos individuos identificados con el nacionalismo y apoyaban una dictadura militar de carácter indefinido, con ello se retrasaría el pronto retorno democrático, y desde lo económico apoyaban una fuerte intervención del Estado no solo dentro del sistema económico, sino que también en los gremios, como los sindicatos. Sin embargo, su poder e influencia era casi nulo por el hecho señalado por Cañas, de que no participaban de las grandes decisiones del poder ${ }^{62 .}$

Los blandos eran los participantes del gremialismo que buscaban la institucionalización del régimen y entrar en un proceso de democratización del país. La institucionalización debía considerar la creación de un nuevo esquema político y de un proceso que legitimara al régimen y el desarrollo de una pronta democratización política. Este grupo tuvo bastantes adherentes que participaron del poder. En lo económico los blandos estaban asociados con los Chicago Boys en cuanto a las visiones liberales de la economía con una menor participación del Estado como agente económico ${ }^{63}$.

Durante el desarrollo político del régimen cívico militar, Pinochet le dio el favor a los blandos y no finalizó el debate entre los adherentes civiles del Régimen, sino que también se inició el debate entre la vieja derecha partidista con los integrantes civiles del Régimen. Ese escenario no solo se desarrolla por la prensa, sino que también por medio de la creación de centros de estudios. Estos fueron lugares de socialización entre la juventud con los políticos que si bien están fuera de la lid del gobierno, mantenían vigente el desarrollo ideológico ${ }^{64}$. Como ejemplo de ello se puede mencionar la Corporación de Estudios Contemporáneos,

60 Correa, Sofía. 2005. Con las riendas del poder, pp.44-46; Correa, Sofía. 1989. "La Derecha en Chile contemporáneo: la pérdida del control estatal”, en Revista de Ciencia Política, $N^{\circ} 11$, p.16

${ }^{61}$ Cañas K, Enrique. 1997. Proceso Político, p. 66.

62 Ibidem, p.91-92.

63 Ibidem.

${ }^{64}$ Rubio, Pablo. 2013. Los Civiles de Pinochet, pp. 93-94. 
fundada en 1978 y dirigida por ex miembros de la Juventud Nacional y de ex parlamentarios como Julio Subercaseaux, que tenían como objetivo "renovar" las prácticas de la derecha política.

Lo anterior nos permite decir que a fines de la década de 1970, la derecha tradicional empezó con un lento proceso de reorganización al margen del fenecido Partido Nacional, dentro de parámetros muy estrechos, dada las limitaciones de la vida política del momento. Si bien había estado bien comprometida con el apoyo al Golpe de Estado y el fin de la Unidad Popular, se observaban hacia 1980 discrepancias públicas por lo extenso del régimen cívico militar, la falta de libertades y la rivalidad frente a los gremialistas y neoliberales, los que hacían notar su diferencia con la derecha tradicional ${ }^{65}$.

\section{La disidencia al régimen cívico militar y las voces del Partido Nacional}

El pluralismo político existente en el Régimen Militar era de carácter limitado, al ser la política partidista considerada como atentatoria al bien común; sin embargo Timmerman señala que hubo desarrollo de actividad política, pero funcional desde el ejercicio de una práctica política que tenía el carácter de ser reducida y funcional al Régimen. Como se ha dicho, el Congreso y los partidos políticos fueron abolidos por las disposiciones de los respectivos Decretos Leyes; dentro de ese margen, esos espacios políticos estaban restringidos a los partidarios del Régimen ${ }^{66}$.

Se debe recordar que las FFAA tuvieron el apoyo activo y voluntario de la elite derechista, desde algunos integrantes del Partido Nacional hasta los gremialistas.

Dentro de ese pluralismo enfocado a los partidarios y del contexto de la pugna entre blandos y duros, empezaron a surgir desde los ex Partido Nacional voces críticas al gobierno, especialmente por medio de la prensa. Cañas en su obra, trató este tema al hablar del surgimiento de una semi oposición y que los sectores vinculados a ella no llegaron a tener una fuerza significativa porque con la autodisolución no se mantuvieron orgánicas institucionalizadas, por otra parte los grupos participantes del gobierno fueron mucho más homogéneos, por lo que la posibilidad de desarrollar críticas a las políticas públicas fueron

\footnotetext{
${ }^{65}$ Cuevas, Gustavo: La renovación ideológica en Chile. Los partidos y su nueva visión estratégica. Editorial Andrés Bello, Santiago, 1993.pp 77-95. En las páginas mencionadas, Julio Dittborn hace una comparación de los aspectos que definen empíricamente (según Dittborn) la derecha tradicional y los lazos que tiene la UDI en el sentido de mejorar esos ejes, dejando claro que la UDI se define como partido de derecha, pero tiene profundas diferencias con la derecha tradicional.

${ }^{66}$ Timmermann, Freddy. 2015. El Gran Terror, pp.179, 180.
} 
escasas $^{67}$. En ese lineamiento tenemos a los grupos nacionalistas, pero también a algunos notables que, sin embargo, se apegaron a la última palabra, lo dicho por el Jefe de Estado.

El régimen cívico militar siempre intentó dar una apariencia de incólume. Sin embargo, sectores importantes de la población que apoyaron al gobierno defenestrado o que no estaban de acuerdo con dar un golpe de Estado para solucionar la crisis de 1973, no simpatizaron con aquél y formarían en las filas de una variopinta oposición sin posibilidades de expresión. Por otro lado, en el campo de las derechas, comprometidas con el surgimiento del gobierno de facto y su apoyo irrestricto, no tardarían en surgir voces disidentes entre los exnacionales. Precisamente, en esta disidencia de derecha está enfocado el presente trabajo.

En los regímenes autoritarios, la oposición y las agrupaciones que tienen disidencias desarrollan sus actividades de forma distinta a la de los tiempos de democracia y que Cañas clasifica asíf ${ }^{68}$ actividad de subsistencia, la cual busca mantener ciertas estructuras de organización mínimas, manteniéndose reunidos los ex Partido Nacional, incluyendo a los no partidarios de la autodisolución; actividad divergente, en la cual se manifiestan disidencias frente al régimen autoritario; actividad opositora propiamente tal, que tiene como foco la legitimidad del régimen, al cual se le busca enfrentar, constituyéndose además en una alternativa democrática, lo cual no fue el caso de los integrantes del ex Partido Nacional, al menos hasta que surgió el PN por el "NO".

Cañas señala con respecto al Partido Nacional que la derecha se sintió representada por la política del régimen cívico militar, por lo que no cabe hablar de que hayan tenido un rol de relevancia como oposición disidente, pero sí hubo disidencias a título personal que claramente no se identificaban con el gobierno ${ }^{69}$.

Algunas entrevistas permiten reforzar aquello, pero para el periodo previo a la apertura política, en que como se ha dicho no hay actividad política partidista permitida, los disidentes hablaban a título personal.

De acuerdo a las fuentes revisadas, Orlando Sáenz es uno de los primeros partidarios del régimen cívico militar en discrepar públicamente por medio de diversas entrevistas.

En 1977 criticó como disidente al Régimen, concordando con Cañas, por cuanto dice "que no aspira a cambiar el régimen, sino en corregirlo" ${ }^{70}$, apelando a su derecho ganado por combatir a la Unidad Popular. Las críticas van enfocadas a diversos temas como "la interdicción política y social a la que se tiene condenado a los chilenos, y la conducción de la

\footnotetext{
67 La semi oposición es un concepto tomado de Juan Linz en que en los regímenes autoritarios, los grupos que si bien apoyan al gobierno, no están representados en la coalición gobernante y que sin oponerse fundamentalmente, desean participar en él.

${ }^{68}$ Cañas K, Enrique. 1997. Proceso Político, pp. 99,100.

${ }^{69}$ Cañas K, Enrique. 1997. Proceso Político, pp. 99,100.

${ }^{70}$ Sáenz, Orlando. “Disidente camino a ser opositor" Revista Cosas N¹4, 7-7-1977, p.12.
} 
política económica y su falta de cohesión con el plano político interno". Además se manifestaba en contra de los cambios porque iban en contra de la esencia de la comunidad y contra la corriente por dos razones: la primera, por el enfoque del modelo económico que tiende a la individualidad y a la desigualdad en tanto no todos tienen las mismas oportunidades; la segunda razón era por la forma operativa del gobierno, no participativa, sino que "es un gobierno autoritario, paternalista", impidiendo al pueblo que tome sus propias decisiones ${ }^{71}$.

Sáenz declaró asimismo que si bien apoyó la instalación del nuevo Régimen, se ha ido desilusionando del gobierno porque más que revolución o cambios, "el único programa real del Régimen es perpetuarse"72.

En 1978 no se observan discrepancias públicas hacia el régimen cívico militar por el contexto provocado por el diferendo austral con Argentina, lo cual de alguna forma logró apaciguar los ánimos. Sin embargo ocurren los sucesos respecto al descubrimiento de restos humanos en los hornos en Lonquén, la destitución del comandante en jefe de la FACH, general del aire Gustavo Leigh y su reemplazo por el general Fernando Matthei.

1979 fue un año de mayor presencia de los viejos nacionales en entrevistas, haciendo énfasis en sus diferencias contra el Régimen. Hugo Zepeda Barros, militante nacional, que fue dirigente del desaparecido Partido Liberal, señaló sus críticas hacia el trato que habían tenido los políticos diciendo "los que hablan pestes contra los políticos ignoran o pretenden ignorar la historia de Chile" ${ }^{73}$, ello tiene que ver con el discurso anti partidos que tuvo el régimen cívico militar a lo largo de su gobierno, y replica que han sido nada generosos con los partidos que combatieron a la Unidad Popular.

La crítica va más lejos por cuanto Zepeda se declaraba partidario del régimen cívico militar, pero pensaba que la existencia de la oposición era fundamental, como también lo era la crítica y es por ello que dice que es "gobiernista crítico", cuestionando a los asesores del Régimen por fomentar el desprecio a los partidos políticos, sin olvidar que "los militares se comprometieron a volver a la democracia y que sin partidos no hay democracia"74. Añadió que los civiles participantes del Gobierno no contaban con los contactos y el respaldo de la civilidad organizada que estaba en esos momentos dispersa y desorganizada. Declarándose partidario de la Junta, Zepeda también manifestó que “...no soy partidario de mantener un

\footnotetext{
${ }^{71}$ Ibidem, p.13

72 Ibidem.

${ }^{73}$ Zepeda, Hugo. "Los que hablan pestes de los políticos ignoran la historia de Chile", Revista Cosas, N 59, 4-11979. p.8.

${ }^{74}$ Zepeda, Hugo. "Los que hablan pestes de los políticos ignoran la historia de Chile", Revista Cosas, N 59, 4-11979, p.8.
} 
régimen de esta naturaleza, autocrático, eternamente. Yo tengo formación democrática... ${ }^{75}$; y por ello entendía que para defender libertades, había que sacrificar derechos, pero no eternamente.

Así mismo Zepeda era uno de los críticos respecto a la nueva institucionalidad que se estaba construyendo, por cuanto la Constitución funcionaría a plazo diferido y avalaba la permanencia de un régimen autocrático; frente a ello señaló "ser partidario que se hubiera reformado la Carta Fundamental de 1925", porque los plazos de inicio de la vigencia de la nueva Constitución, como la transición al retorno democrático estaban en una nebulosa ${ }^{76}$.

Y sobre el tema partidario, como militante del ex Partido Nacional aclaraba que no estaban en el Gobierno, salvo algunos casos de algunos militantes destacados en el periodo previo a 1973, los cuales ocupaban algunos cargos menores, pero no tienen relación con el partido; y hace mención que "Fernando Ochagavía es su presidente". A lo cual la periodista le pregunta ¿ah, sí? ¿Cuándo lo eligieron?, Zepeda se ríe y dice "ahora no hay elecciones"77; pero se refería al rol del ex senador Ochagavía como presidente del Club Fernández Concha.

En el caso de Orlando Sáenz, sus opiniones de disidente pasaban a ser de clara oposición en cuanto su fundamento se basaba en la falta de libertades, el modelo económico, el tema de derechos humanos y la persecución a los opositores ${ }^{78}$; para él, había una necesidad de cambios porque las FFAA entraron a una etapa de desgaste de sus valores institucionales y que la influencia de estas en el gobierno había sido "extremadamente baja".

Por otro lado, la figura de Julio Subercaseaux Barros, que fue dirigente del Partido Conservador y luego vicepresidente del Partido Nacional, no quedó conforme con el lado nacionalista del partido por ser "muy peligroso"

El rol de Subercaseaux no fue menor por cuanto firmó una declaración pidiendo al gobierno que devolviera a los chilenos su calidad de ciudadanos, manifestándose como opositor al régimen cívico militar; por ello afirmó "que hay que reorganizarse, formar partidos políticos porque la oposición tiene la posibilidad de forjar una alternativa válida...". Cree que es necesaria una oposición a dos bandas; por un lado los demócrata cristianos y por otro lado elementos de derecha junto a radicales y socialistas moderados, porque "cualquier unión es válida si se cree en la democracia"; sin embargo, reconoce su apoyo inicial al gobierno y su

\footnotetext{
75 Ibidem.

76 Ibidem.

${ }^{77}$ Ibidem, p.9.

${ }^{78}$ Sáenz, Orlando. "Para un izquierdista, yo soy un burgués redomado", Revista Cosas, 23-3-1979, pp. 68,69.

${ }^{79}$ Subercaseaux, Julio. "Este régimen parece identificarse con la derecha pero no es asi", Revista Cosas, 12-4-1979, pp. 68,69 .
} 
temor al marxismo y a la violencia ${ }^{80}$. Cuestionó al gobierno diciendo: “...me temo que lo que quiere no es ir a una institucionalidad a corto plazo, sino de hacer tiempo. Porque vemos que el Gobierno trata de perpetuarse", y hace el énfasis de que "el régimen no se identifica con la derecha, parece identificarse, pero no es así...". Al igual que Zepeda, Subercaseaux hizo la crítica por el desprestigio de los políticos por parte del gobierno y que hay gente de derecha trabajando en el gobierno pero como mal menor. Eso sí, desliza que el régimen no se identifica con la derecha pero si con la derecha económica: "derecha económica de muy distinto cuño. Yo pienso que surgió sobre la base de representación de capitales extranjeros. No es la derecha económica criolla". Sobre la derecha y su alma dice Subercaseaux: "ser de derecha es aprobar todo lo que había sido Chile hasta ahora. Es aprobar la tradición del país. Es aprobar el hecho que tratamos de hacer un país a la usanza occidental" ${ }^{81}$. Frente a la pregunta de por qué los militares se inclinaron por la derecha, el entrevistado dice que "la derecha ofrecía poca consistencia política...", frente por ejemplo a los demócrata cristianos que podían haber sido un fuerte contrapeso ${ }^{82}$.

Respecto al proyecto constitucional, discrepa completamente porque "está empapado de la Doctrina de Seguridad Nacional, luego, no considera al Congreso para nada...en suma, tal como el régimen, esta empapada de franquismo" ${ }^{83}$.

El caso de los viejos liberales es más patente con la opinión de Patricio Phillips, quien al comienzo de su entrevista señaló: "una cosa es la manera de pensar y la otra es la persecución ideológica. Eso no va conmigo", afirmó, reconociendo que fue partidario de "botar" el gobierno de Allende, y criticó a los que en este momento daban recetas para el país, pero habían arrancado de Chile después del 4 de septiembre de $1970^{84}$. Además, declaraba estar descontento con los resultados de la Comisión Ortúzar "porque tiene que haber un equilibrio de poderes...Porque si bien es necesario que haya un ejecutivo con atribuciones fuertes, también hay que considerar ciertas cosas como las libertades que son inherentes al hombre, que deben quedar en la Constitución y no estar a disposición del Gobierno" ${ }^{85}$.

Respecto al régimen cívico militar dijo que "las dictaduras se saben cuándo comienzan y no cuando terminan..." ${ }^{86}$; y que para volver al retorno democrático "yo no diría si hay que esperar más tiempo. Lo importante es si las condiciones están dadas o no". Con respecto al

\footnotetext{
${ }^{80}$ Subercaseaux, Julio. "Este régimen parece identificarse con la derecha pero no es asi”, Revista Cosas, 12-4-1979, pp. 68-69.

81 Ibidem.

82 Ibidem.

83 Ibidem.

${ }^{84}$ Phillips, Patricio: "Los liberales nos estamos organizando en todo el país", Revista Cosas 16-8-1979, p.16.

85 Ibidem.

${ }^{86}$ Ibidem.
} 
apoyo a la salida militar señala que hubo golpe gracias a los nacionales y demócrata cristianos y que el pecado fue no haber pactado con los golpistas; por ello culpó a Sergio O. Jarpa: "Lo que pasa es que Jarpa era partidario ciento por ciento del golpe y no del sistema democrático. Yo creo que de donde él viene, eran nazistas... pero el grueso de nacionales y liberales no lo son" $^{\prime \prime 7}$.

En 1980 antes del plebiscito constitucional, Hugo Zepeda vuelve a la palestra declarándose partidario del Régimen Militar, pero reconociendo que discrepa en un aspecto, y ese es el tema constitucional ${ }^{88}$.

Ya desde los trabajos de la Comisión Ortúzar ${ }^{89}$ se formaron grupos de especialistas tanto de la oposición al régimen cívico militar como de grupos disidentes para observar críticas al anteproyecto redactado y pronunciarse finalmente por la opción NO. Al respecto Zepeda afirmó: "Yo considero que el NO, en esa hipótesis no significa un rechazo a las Fuerzas Armadas, sino que un rechazo a las disposiciones transitorias que se quieren imponer en una sola votación, conjuntamente con la Constitución Política" ${ }^{90}$.

Carlos Reymond señaló que en Chile "no hay debate político, no hay participación política, no hay órganos políticos y miedo a la democracia". Además manifiestó su descontento contra el articulado transitorio que no es democrático, que los plazos para el retorno a la democracia eran largos y peligrosos por existir un riesgo de un desgaste político y por ende de las FFAA, y el temor a lo anterior era por los traumas del periodo pre $1973^{91}$. Si bien se declaraba partidario del Gobierno, discrepó sobre el uso de las medidas represivas que no le gustaban ni a él ni a nadie, incluso al propio Gobierno ${ }^{92}$.

Phillips señaló en 1982 que se sentía aval del gobierno, pero no incondicional de nadie y respecto a la derecha en el régimen señala: "Yo creo que hay grupos que no representan a la derecha, que han pretendido administrar al gobierno, que han querido ser alternativa, y que se toman la representación de la derecha sin tenerla. No han conseguido representarla ni menos darle el respaldo político que necesita el gobierno" ${ }^{\prime 3}$.

\footnotetext{
${ }^{87}$ Ibidem, p.17.

${ }^{88}$ Zepeda, Hugo. "Pase lo que pase el día 11, la idea de volver a la democracia seguirá presionando". Revista Cosas, 10-9-1980, pp. 16-18.

${ }^{89}$ Comisión de Estudios de la Nueva Constitución Política, presidida por el abogado Enrique Ortúzar, que elaboro el anteproyecto constitucional.

90 Ibidem, p.17.

91 Reymond, Carlos: "Los chilenos no vamos a volver al marxismo. No somos un pueblo de interdictos o débiles mentales". Revista Cosas, 17-6-1982, p.17.

92 Ibidem.

93 Phillips, Patricio: "El camino constitucional va a dar a la democracia, quiéranlo o no". Revista Cosas 7-10-1982, pp. 64-65
} 
Sin embargo Phillips reconoció haber votado por el Sí en la consulta de 1978 y en el Plebiscito Constitucional de 1980, en esta última situación previa consulta a Jorge Alessandri, a falta de algo mejor, y que debería ponerse en práctica ${ }^{94}$.

En otro aspecto, Rubio señala que las atribuciones de Pinochet y lo extenso del mandato contemplado para que el ejecutivo fuese plebiscitado, fueron focos de conflictos entre los grupos de derecha en Chile. Mientras los gremialistas no apoyaban la apertura política y criticaban a la democracia liberal, hubo grupos de nacionales que abogaban por una pronta restauración democrática ${ }^{95}$.

Se concuerda con el autor en que la relación existente de la Junta Militar con la derecha política tradicional es difícil de entender por cuanto están los factores de la autodisolución del Partido Nacional, el trato a las figuras políticas del periodo y cómo los militares anularon en cierto modo la relación al impedir la mantención de una orgánica funcional.

Se destaca dentro de la retórica anti partidos que el Régimen haya tenido que recurrir a sectores civiles que se declaraban de derecha, pero sin ser originarios del tronco histórico tradicional de los partidos. Esto provocó que se codearan con el régimen cívico militar dotándolo de un proyecto de transformaciones estructurales tales como el modelo económico de mercado y el nuevo armazón constitucional, recibiendo a cambio el acceso a puestos claves, provocando como efecto, un desafío a la derecha tradicional que perdió los espacios de poder, dejando entonces que la nueva derecha surgida de la coalición gremialista-Chicago se mantuviera por los apoyos recíprocos con el régimen de Pinochet.

Benavente por otro lado, opinó que a la derecha tradicional se mantenía en la inercia y que en plena crisis andaba buscando el espacio perdido en que los chilenos no habían advertido que apoyaron al régimen por la omisión. Pese a ello, había un sector democrático en que encajaban Zepeda y Subercaseaux, y que se había mantenido consecuente con los principios republicanos y libertarios ${ }^{96}$.

Engelberto Frías continuó la tónica de los dirigentes Nacionales en cuanto a tener posturas críticas frente al gobierno en varios aspectos. Señaló: "Nos equivocamos. Hemos sido demasiado cautos, demasiado considerados. Hemos entregado el campo...no estamos organizados. Cuando venga el cambio, a nosotros nos pillaran confesados. Hemos llevado nuestra colaboración hasta el silencio, pero la etapa de silencio terminó" ${ }^{97}$.

\footnotetext{
94 Ibidem, p.64.

95 Rubio, Pablo. 2013. Los Civiles de Pinochet, p.101.

${ }^{96}$ Benavente, Andrés: "La derecha anda en busca del espacio perdido "Revista Cosas, 4-11-1982, p.78.

97 Frías, Engelberto: "El gobierno debe llamar a hora a los grupos políticos que pueden apoyarlo", Revista Cosas №160, 18-11-1982, p.34.
} 
Reconoció que el silencio fue un error, pero no visto como suicidio político, sino como una forma de colaborar con un gobierno que al asumir, tenía muchos problemas, y que pese a eso, las convicciones siguieron intactas con lo que la etapa del silencio terminaba porque el régimen cívico militar estaba huérfano de todo apoyo organizado y descapitalizado políticamente $^{98}$.

Además Frías señalaba que el balance del gobierno en nueve años no eran bueno, especialmente por los efectos de la crisis económica que se empezó a desatar ese mismo año 1982. Pronosticaba además que, dado el descontento por la situación existente, el gobierno debería incorporar a los demócratas en la administración y gestión del país que "sea partidaria de un régimen de libertad, respeto por los derechos humanos y antimarxista" ${ }^{99}$.

El punto citado no deja de ser interesante, porque marca un aspecto que tiene en común la derecha partidista tradicional, con la nueva coalición civil compuesta por los gremialistas con los Chicago: el anti marxismo ${ }^{100}$.

Pero declara que si no hay respuesta del régimen cívico militar a las necesidades de cambiar el esquema, no le queda otra opción que articularse y unir a la gente que piensa en la democracia, extendiendo la invitación a democratacristianos y socialdemócratas por la preocupación por la suerte del país, que en este caso no es solo el destino del régimen sino que el enfrentamiento al marxismo como opción de llegar al poder ${ }^{101}$. Respecto a ello señala que la cuestión del exilio y su fin no es algo menor; y critica que se hubiese exiliado a demócratas como Andrés Zaldívar y Jaime Castillo Velasco ${ }^{102}$.

En el tema de los derechos humanos se observaba cierto sentimiento de culpa por no levantar la voz, cuando Frías dijo: “¿usted cree que en plena bonanza económica como la que hubo, íbamos ir a plantear públicamente lo de los derechos humanos? Nos habrían tildado de locos", y repara que en los años anteriores se hicieron observaciones al régimen cívico militar de manera privada y que no se les hizo caso, y que ahora dada las circunstancias de debilidad del gobierno les escucharían ${ }^{103}$. Sin embargo, respecto al futuro del régimen y sus herederos opinó: "Este gobierno no tiene herederos políticos y en todo caso no debiera tenerlos, porque este país debería ser dirigido por la gente que realmente cree en la democracia. Por la gente

\footnotetext{
98 Ibidem, p.35.

99 Ibidem.

100 Ibidem.

101 Frías, Engelberto: “El gobierno debe llamar a hora a los grupos políticos que pueden apoyarlo", Revista Cosas №160, 18-11-1982, p.35.

102 Ibidem.

103 Ibidem.
} 
que verdaderamente respeta los derechos humanos...De manera que los herederos políticos van a ser las grandes mayorías, es decir el centro [político]"104.

En 1983, que fue el año del inicio de la vuelta a la vida política, Francisco Bulnes vuelve a hacer críticas al gobierno en el sentido de decir "estamos desencantados y alarmados por el hecho de no estar viviendo un verdadero periodo de transición a la democracia, sino una simple prórroga de la etapa anterior, endurecida..." ${ }^{105}$, señalando que las libertades estaban restringidas, había menor participación política y el gobierno carecía del criterio de escuchar. A partir de lo anterior señalaba que al gobierno le faltaba transparencia para lo que había sido la toma de decisiones y la incapacidad de este de escuchar opiniones fuera de las fuerzas armadas y del equipo económico, por lo que las críticas eran en los ámbitos político y económico.

Bulnes comienza a hablar del destino del Partido Nacional. Cuando da su opinión de los diversos llamados de unión de ese partido, señalaba que gran parte de los nacionales, incluido él, eran democráticos, salvo algunas excepciones..., habiendo reafirmado la fe en la democracia como sistema formal de gobierno, y que la derecha democrática iba más allá de algunas personas o grupos de estudio, haciendo énfasis que quienes participaron del gobierno siendo de origen nacional, estaban allí a título personal ${ }^{106}$.

Sobre la relación con los gremialistas, Bulnes señalaba que si querían actuar en política tendrían que hacerlo con la derecha, porque los pensamientos son bien parecidos, énfasis que se da con la diferencia que tienen los gremialistas respecto a los duros ${ }^{107}$.

\section{Conclusiones}

La derrota parlamentaria de 1965 logró que el Partido Conservador y el Partido Liberal se pusieran de acuerdo en fusionarse e incluir en ello a Acción Nacional, con lo cual se originó el Partido Nacional, como partido instrumental para combatir tanto al populismo comunitario de la Democracia Cristiana como a los proyectos inspirados en el marxismo leninismo. Esta visión combativa le dio réditos, logrando recuperar de alguna manera su caudal electoral y con ello enfrentar de mejor manera las elecciones presidenciales de 1970, cuyo resultado adverso provocó que el Partido Nacional formara una dura oposición al Gobierno de Salvador Allende, especialmente en el periodo 1972 y 1973, apoyando la resistencia civil al gobierno de Allende y llamando inclusive a la intervención militar para poner fin, según su perspectiva, a la crisis de

\footnotetext{
104 Ibidem.

105 Bulnes, Francisco: “El gobierno debe encabezar ahora una verdadera transición”, Revista Cosas, №166, 10-21983, p.10.

106 Ibidem, p.12.

107 Ibidem.
} 
convivencia política y la profunda división que afectó a toda la sociedad chilena durante aquel periodo.

El Golpe de Estado del 11 de septiembre de 1973, declaró el fin de la vida política nacional y su reemplazo por un régimen armado en que las Fuerzas Armadas tomaron el control del Gobierno y del Poder Legislativo, marginando de toda toma de decisiones a los partidos políticos, tanto a los afines al fenecido Gobierno de la Unidad Popular, como a los opositores. En el caso del Partido Nacional es conocida su autodisolución, pero quedaba claro que no fue por acuerdo unánime. Esto evidenció que la unidad dentro del Partido Nacional no fue algo monolítico, notándose dos bandos y sus posturas: el Liberal - Conservador y los Nacionalistas. El Bando liberal-conservador que no estuvo por la disolución del partido; y los nacionalistas que aceptaron de buena gana el cambio de régimen y con ello el fin de la vida partidaria pública como actividad.

El receso autoimpuesto por los nacionales de manera voluntaria provocó un espacio de vacío en la vida política, por cuanto la izquierda se mantuvo en la clandestinidad y la Democracia Cristiana prosiguió con su institucionalidad intra portas. En la derecha, este espacio fue ocupado por los partidarios del régimen, los que conformaron un sector "duro" y un sector "blando", teniendo mayor gravitación en el Régimen los blandos, vinculados al gremialismo.

En el transcurso de los primeros años del Régimen, se observó un silencio sepulcral de los viejos militantes del Partido Nacional; ello porque la mayoría retornó a sus actividades particulares o privadas luego del receso y los menos, ocupando cargos públicos de mediana relevancia como embajadas, alejándose de los centros de poder y por ende, de la toma de decisiones. Pero finalizando la década se observaron las primeras voces disidentes de la vieja derecha partidista frente a las políticas de la dictadura cívico militar, respecto a los siguientes temas: manejo económico, posición contra el exilio, aprobación de la Constitución Política de 1980.

Las críticas fueron hechas a título individual, sin tener una voz clara e institucional como partido político o corriente de opinión. Cada uno de estos nacionales que emitieron estas discrepancias, a medida que transcurrió el tiempo, fueron adoptando diversas posiciones. Unos fueron más cercanos al régimen: Francisco Bulnes, Patricio Phillips o Carmen Sáenz; otros asumieron posturas más alejadas, como Engelberto Frías, Germán Riesco y Pedro Correa; o pasando en algunos casos a ser francos opositores como Julio Subercaseaux y Hugo Zepeda Barrios. Junto con ellos el empresario industrial más crítico fue Orlando Sáenz, quien, si bien no militó en el Partido Nacional, estuvo muy cerca de él. Estas voces críticas se hicieron notar en la prensa, especialmente en entrevistas directas. 
En 1983 el Partido Nacional resurge y tiene una vida breve pero intensa, cuyo epílogo lo firma la definición para el Plebiscito de 1988, en que el Partido Nacional se divide entre los que apoyan la opción Sí y los que apoyan la opción NO, terminando de extinguirse durante la década de 1990 por la poca votación obtenida en las elecciones, subsumiéndose entre los partidos de la derecha y de la centro izquierda.

\section{Fuentes y bibliografía}

\section{Fuentes Hemerográficas:}

Benavente, A. "La derecha anda en busca del espacio perdido", en Revista Cosas, No 159, 4 de noviembre de 1982, Santiago, p. 78.

Bulnes, F. "El gobierno debe encabezar ahora una verdadera transición”, en Revista Cosas, N¹66, 10 de febrero de 1983, Santiago, pp. 10-12.

Frías, E. "El gobierno debe llamar ahora a los grupos políticos que pueden apoyarlo", en Revista Cosas, $\mathrm{N}^{\circ} 160,18$ de noviembre de 1982, Santiago, p.34.

Jarpa, S. "Actualmente nadie puede atribuirse la representación del Partido Nacional", en Revista Cosas, $N^{\circ} 167,24$ de agosto de 1983, Santiago, p. 11.

Phillips, P. "Los liberales nos estamos organizando en todo el país", en Revista Cosas, №75, 16 de agosto de 1979, Santiago, pp. 16-18.

Phillips, P. "El camino constitucional va a dar a la democracia, quiéranlo o no", en Revista Cosas, № 157, 7 de octubre de 1982, Santiago, pp. 64-65.

Reymond, C. "Los chilenos no vamos a volver al marxismo. No somos un pueblo de interdictos o débiles mentales", en Revista Cosas, № 149, 17 de junio de 1982, Santiago, pp. 16-17.

Sáenz, O. "Disidente camino a ser opositor", en Revista Cosas, N¹4, 7 de julio 1977, Santiago, p. 12.

Sáenz, O. "Para un izquierdista, yo soy un burgués redomado", en Revista Cosas, № 65, 23 de marzo de 1979, Santiago, pp. 68-69.

Subercaseaux, J. "Este régimen parece identificarse con la derecha pero no es asi", en Revista Cosas, $\mathrm{N}^{\circ}$ 66, 12 de abril de1979, Santiago, pp. 68-69.

Zepeda, H. Los que hablan pestes de los políticos ignoran la historia de Chile", en Revista Cosas, $N^{\circ} 59,4$ de enero de 1979, Santiago, p. 8.

Zepeda, H. "Pase lo que pase el día 11, la idea de volver a la democracia seguirá presionando", en Revista Cosas, $\mathrm{N}^{\circ} 103,10$ de septiembre de 1980, Santiago, pp. 16-18.

\section{Diarios}

Partido Nacional. "Junta Militar abre una nueva etapa histórica", en Diario Tribuna, Santiago, 21 de septiembre de 1973.

Jarpa, S. ¿Cuánto tiempo debe gobernar la Junta Militar?, en Diario Tribuna, Santiago, 24 de noviembre de 1973.

\section{Bibliografía}

Arancibia, P. 2000. Jarpa: conversaciones políticas, Santiago, Ediciones Mondadori-La Tercera.

Arellano, J.C. 2009. "El Partido Nacional en Chile. Su rol en el conflicto político (1966-1973)", en Atenea, $\mathrm{N}^{\circ}$ 499, Concepción, pp. 157-174.

Bravo, B. 1978. Régimen de gobierno y partidos políticos en Chile 1924-1973, Santiago, Jurídica de Chile. 
Cañas, E. 1997. Proceso Político en Chile. 1973-1990, Santiago, Andrés Bello.

Contreras, M. y González, E. 2014. Las derechas en Chile (1958-1981), Valparaíso, Ediciones Universidad de Valparaíso.

Corvalán, L. 2002. Del anti capitalismo al neoliberalismo en Chile. Izquierda, centro y derecha en la lucha entre los proyectos globales, 1950-2000, Santiago, Sudamericana.

Correa, S. 1989. "La Derecha en Chile contemporáneo: la pérdida del control estatal", en Revista de Ciencia Política, N¹1, Santiago, pp. 6-19.

Correa, S. 2005. Con las riendas del poder. La derecha chilena en el siglo XX, Santiago, Sudamericana.

Cuevas, G. 1993. La renovación ideológica en Chile. Los partidos y su nueva visión estratégica, Santiago, Editorial Andrés Bello.

Fernández, M.E. 2017. "Conformación de Partidos Políticos en Chile", en Jaksic, I. y Ossa, J.L. (eds.), Historia política de Chile, 1810-2010. Tomo I: Practicas Políticas, Santiago, Fondo de Cultura Económica, pp 149-178.

Rubio, P. 2013. Los Civiles de Pinochet. La derecha en el Régimen Militar Chileno, 1983-1990, Santiago, Dirección de Bibliotecas, Archivos y Museos (DIBAM).

Sepúlveda, S. 2018. Una disidencia derechista al régimen cívico militar chileno: Partido Nacional (19831988), Concepción, Universidad de Concepción, Tesis para optar al grado de Magister en Historia, pp. 10-14.

Timmermann, F. 2015. El Gran Terror. Miedo, Emoción y Discurso. Chile, 1973-1980, Santiago, Ediciones Copygraph.

Váldes, M. 2015. El Partido Nacional: 1966-1973, Madrid, Universidad Nacional de Educación a Distancia (UNED), Tesis para optar al grado de Doctor en Historia.

Valdivia, V. 2006. Su revolución contra nuestra revolución. Izquierdas y derechas en el Chile de Pinochet (1973-1981), Santiago, LOM Editores.

Valdivia, V. 2008. Nacionales y Gremialistas. El parto de la nueva derecha política chilena, 1964-1973, Santiago, LOM Editores. 